\title{
The Potential of Cinematic Language in Geography Education and the Relationship among Communication, Culture and Geography
}

\author{
Gabriela Candeu \\ University of São Paulo, São Paulo,Brazil, gabrielacandeu@hotmail.com
}

\begin{abstract}
From the beginning of geographic thought, authors like Kant, Humboldt, and, Vidal de La Blache made reference to the necessity of the images in the construction of geographic thought. Nowadays, new interpretation of this correlation is worthwhile because of the intensity of images, and in this case, films that children and young people are exposed to daily, without necessarily understanding the geography behind the creation of these symbols and meanings. Due to this phenomenon, this research is based primarily on identifying the need to incorporate these languages into teaching, in a way that is not just illustrative. The need for this incorporation is to enable students to develop critical geographic thought around these constant images, while creating a closeness between the geographic content and the cultural life of students. The purposes of this practice were to provoke the student's to make the act of watching a movie an exercise of geographic thought. The research was carried out with an extensive bibliographical investigation to support the practical part of the project executed in two schools in the city of São Paulo. At the conclusion, the potentialities of the work with cinematic language in geography education were evident, as well as an analysis of the main problems of this interdisciplinary practice.
\end{abstract}

KEYWORDS: geographic tought, geographic education, cinematic language, interdisciplinary practices

\section{Introduction}

We live in an era of images, where our location, our culture, information and socialization are first conveyed by images. Children today are exposed to images, movies, and video games before they even go to school. Faced with this reality we can observe that young people are being educated primarily by images rather than by writing.

We asked ourselves questions like: What is the impact of this excessive consumption of images on students' lives? How are they absorbing this content? How does this affect school education? And how can school education use these resources as potentialities?. Faced with these questions, we developed an interdisciplinary didactic between cinematic language and geography education, as well as in relation to other disciplines. This practical work was developed during one year in two different schools. Always, seeking to observe the potential, problems and limits of this proposal in the school environment.

Our practical work was focused on to create the possibility for students to learn to "read" an image or a scene. To provide them the tools to reflect on the geographic thinking behind the construction of a film. To create the possibility so they can to become active thinkers of this language and not just passive consumers of such ideologies. What we bring here are the main observations made during this work. We seek to share all the potentialities, problems and limits presented in this research. Based on this premise, this research was mainly influenced by concepts of the humanities, such as geography, education, cinema and communication, with the intention of basing the research on interdisciplinary studies.

\section{The relationship among Culture, Communication and Geography}

Everything we think about, any immaterial idea conceived in the relationship between man and the environment, its relations of power, economy and politics, when it becomes material, characterized by space, location and territory, is geography. The culture in this case can be understood as the "Geography of Diversity," because it is the form of thoughts and habits of a certain population materialized in a piece of land, having influences from others, but having always been singular. It is not today that we think about the relationship between geography and culture. Authors like Richard Hartshorne and Carl Sauer, have 
studied this relationship since the last century. What is important today is to rethink our reality, and especially the reality of school students regarding these concepts.

Currently, we live in a globalized reality. We do not have to travel to the other side of the world to know another culture. We can know them by our computers, cell phones, or simply turn on the television and access the cultures of the most remote civilizations in the world. What we mean is that according to the speed of communication available today, the way we are accustomed to learning and teaching about geography and culture, until the beginning of the $20^{\text {th }}$ century, is no longer compatible anymore with the access that children and youth have today. What we mean is that it is inside the school where we can see the difference between the way knowledge was created, and how it is currently being incorporated by this new generation.

From this framework, our research began with a reflection of how communication impacts on the way young people are learning and appropriating their cultural concepts, and how our students can be passive in the face of the excess of images they are exposed to daily, while these concepts are not addressed in school.

In this context, for us, the relationship between culture, communication and geography is also within the school, in the need to renew the structure of education that has been standard in the school environment for decades, and that today distances our students, members of a new information age, who are excluded from this constriction of knowledge because they believe they "speak another language." We believe that any knowledge, as well as geographic thought, is perceived in the way of your looking around, and can be in any kinds of communication languages.

\section{The Potential of the Cinematic Language in Geography Education}

The written text is always the most important reference, where one has the possibility to go back, to think, to reflect. But "we cannot fail to think that ourselves, in part, and a majority, are totally forming our intelligibility of the world from the images and sounds of the productions of cinema and television" (Almeida 2004, 8). Almeida refers to people who are immersed in the universe of mass communication, illiterate, semi-literate, that do not properly have a memory of writing and reading. "This actual closeness of images has a configuration very close to orality, which explains, in part, the fact that images are sometimes stronger than a text" (Almeida 2004, 9).

In this way, it is important not to see cinema, as an image, as a didactic or illustrative resource, but to see it as a cultural object, full of potentialities, and inherent in the lives of these young people and children. The author states "Watching movies, analyzing them, is the will to understand our mass society, practically illiterate and who does not have a memory of writing. A society that is educated by images and sounds, mainly by television" (Almeida 2004, 12).

In the last twenty years, geography teaching has undergone many transformations. In part, this process of renewal started from criticisms of traditional teaching based on the memorization of facts and concepts and the conduction of encyclopedic knowledge, merely descriptive and largely unrelated to reality. It is from this interaction between these images and narratives, singularities and multiplicities, that we find the great trump of cinematic language and its approximation with the lines of thought contained in geography. By instituting other senses of reality, cinema is pointing to other potential senses of orientation and spatial location of phenomena. Doreen Massey states that "Geography cinema allows us to better address the essential multiplicity of space" (Massey 2008, 111), this overcoming the tradition of the idea of limited linear evolution of the world to its unique extension of the world.

We try here to show students how geography is present in every form of human or natural relationship, whether social, political or economic. Geography already exists as long as it is part of the construction of the student's gaze. We work on making geography as present in the student's life as cinematic language and the language of imagery. The potential of cinema in the teaching of geography is the power to find it, to perceive it and to make it exist, simply by thinking it, in whatever reality, image or scene, whatever it may be. 


\section{Practices with Cinematic Language in Geography Education}

After the theoretical research, two practices were performed to verify if the potentialities of the cinematic language in geography and interdisciplinary teaching are effective. These practices were both developed in public schools in the city of São Paulo, Brazil. It is not appropriate here to explain in detail each step taken within the school. It was a long research project carried out weekly during the course of a year, which generated extensive material. The purpose here is to share the methodology created during the implementation of these actions, which showed better results in working with cinematic language in teaching. The potentialities were found as well as their problems and limitations. We focus here on presenting a contribution to make this practice more present within the school environment, as well as the discussion of new possibilities in teaching between teachers and researchers around the area. The proposal of working in cinematic language to develop the contents of the disciplines is not related to using them in an illustrative way, but in a rather reflective way. The object in analysis can be implicit, explicit or even camouflaged in the film's plot.

The first practical aspect of the method developed was the use of objective scenes rather than an entire movie because each class lasts an average of only forty-five minutes. Using the scene allows teachers to address specific topics briefly, leaving free time for a conversation or activity wheel. Another reason is that the use of a brief scene draws more attention from the student about the subject than if the whole movie is presented. This strategy allows key elements to be perceived because they do not contain the entire narrative of the film, and it gives the teacher time to use other languages at work, in the same class.

In addition to observing the best development of the practice, it was noted that the best time to present the scene is at the beginning of the class. We suggest that the scene be shown without anticipated presentation or contextualization. From one year of practical experience, it has been observed that since the moment when the lights go out, the students' attention shifts, and a focus is created. Without knowing what it is, students begin to make approximations and comparisons about what is being shown. They seek to create understanding, even to formulate a line of reasoning about what is being watched.

After watching the scene, we realize that are not so productive when we continue with an explanation of the film or about its content relationship than when we continue by asking students questions. We propose a practice similar to the Socratic method, in which, through questions and answers, we lead students to find for themselves the relationship with the contents. This method allows students to perceive less explicit layers in the film, such as: Positioning the camera in choosing what is to be seen or not; if the scenery is natural or built; and if there are brands or companies sponsoring the production and what their interest is. In general, we seek to lead students to a reflection on the signs and meanings implicit in the film that in turn relate to the geographic or interdisciplinary concepts. This practice of letting students make connections through scenes creates a rapport between geographic thought and student life, enhances the knowledge brought by students to school and promotes dialogue among the class.

It is important to emphasize that this work makes the teacher play the important role of mediator and conductor of the class, giving focus to certain content to be worked on, and directing the discussion of the scene after it is shown. It is also important that the teacher encourages interest in the discussion in the students and makes the students feel that they have something to contribute to the class, until they develop their geographical thinking through the images. This role is essential for the potential of cinematic language to be effective during the practice.

As this practice is developed during class, concepts will increasingly become visible to students and close to their realities, making watching a movie or viewing an image an exercise in the student's geographic thinking. It has been seen, that once students are familiar, they themselves see the geography behind video games, advertisements and even television programs. 


\section{Analysis and Discussion}

During the work, analyses and discussions were conducted on some topics such as the technical support of the school to work with films and aspects of the teaching career that impact on this type of practice as well as on teacher training.

Regarding technical support, none of the schools had a proper video room or materials like a television or projector to watch movies within the classrooms. The activities in both schools were held in the library. The room should be reserved in advance and shared as needed by all teachers. However, due to the need to change the classroom, about five to ten minutes per class is lost to make this transition, which becomes a barrier to achievement. Due to this scenario, it is up to us to reflect on the necessity of having multi-language equipment in all classrooms.

Our analysis of teacher career and training is also based on a study conducted by us prior to this research, which was applied to a questionnaire with twenty-six geography teachers from different schools in the state of São Paulo, Brazil. As an important result, we confirm that over ninety percent of teachers said they had not received preparation during their training to work with these media languages in class, as they do not believe they are able to perform these activities in a way that is not just illustrative. On the other hand, one hundred percent of respondents said they always use these imagery and film features in their classes. These data make us reflect on the need to incorporate these resources not only at school, but also at university, so that teachers feel in command of these tools for better student learning performance. With these aspects we have to point out the need for the support of continuing training for teachers who are already working, so that they can also create new possibilities equivalent to the reality of this new generation of students.

To conclude our analysis we focus on the school's role in providing this openness for the teacher, as well as having these activities as part of a monthly or annual planning by the school, so that teachers can dialogue with each other, share experiences and even promote interdisciplinary practices. Thus, we encourage collective and horizontal work within the school, between the principal and the teachers.

\section{Conclusions}

At the end of the practice, we reflected on how to analyze if the methods were really effective during the research. We think that the best form of analysis would be to develop a way of having the students themselves answer our questions about whether or not these activities were effective.

At the end of the first practice of six months, a qualitative questionnaire was administered to more than ninety students to obtain their personal answers about the activity. In the second practice of six months, we administered the questionnaires to more than two hundred students and changed them from qualitative to quantitative with multiple choice questions and answers. Moreover, a group activity was developed to evaluate the effectiveness of the exercise of "reading" images and scenes. In this activity, each class was asked to divide into six groups of an average of five students. Then they were asked to choose any subject from the course work, to be presented with a scene from a movie, and then to relate to the subject. This activity gives students the opportunity to bring scenes of their choice, shows their way of viewing content in images, creates incredible learning potential and develops "reading of images and scenes."

From all theoretical and practical research, as well as the collected data, we conclude that the potentialities of working with the cinematic language in the teaching of geography, as well as in the other disciplines, are innumerable. On the other hand, in order for these potentialities as well as many others to happen, it is extremely necessary that this work be guided by the meetings that define the new paths that school education is treading, as well as the role of the university and researchers in this discussion that both impacts and defines teacher education around the world. 


\section{References}

Almeida, Milton. 2004. Imagens e Sons, Rio de Janeiro: Cortez Editora.

Deleuze, Gilles; Guatarri, Félix. 1992. O que é Filosofia? Rio de Janeiro: Editora 34.

Girotto, Eduardo; Mormul, Najla. 2016. Formação Docente e Educação Geográfica: entre a escola e a universidade. Curitiba: Ed. Curitiba CRV. V1.

Gomes, Paulo; 2017. Quadros Geográficos: uma forma de ver e uma forma de pensar. Rio de Janeiro: Bertrand Brazil.

Hartshorne, Richard. 1939. The Nature of Geography. Lancaster, Penn. Annals on Association of American Geographers, XXIX

Kant, I. 1802. Géographie-Physische Geographie. Paris: Aubier.

Massey, Doreen. 2008. Pelo espaço: uma nova política da espacialidade. Rio de Janeiro: Bertrand Brasil. Sauer, Carl. 1925. The Morpholologi of Landscape. Berkeley: University Press.

Vidal de la Blache, Paul. 1921. Principes de Géographie Humaine. Paris: A. Colin. 